\title{
Cell Line
}

National Cancer Institute

\section{Source}

National Cancer Institute. Cell Line. NCI Thesaurus. Code C16403.

A permanently established cell culture that will proliferate indefinitely given appropriate fresh medium and space. 